\title{
Stock Return Volatility And Trading Volume Relationships Captured With Stable Paretian GARCH And Threshold GARCH Models
}

Atsuyuki Naka, University of New Orleans, USA

Ece Oral, Central Bank of the Republic of Turkey, Turkey

\begin{abstract}
This paper examines the volatility of Dow Jones Industrial Average stock returns and the trading volume by employing stable Paretian GARCH and Threshold GARCH (TGARCH) models. Our results indicate that the trading volume significantly contributes to the volatility of stock returns. Additionally, strong leverage effects exist with negative shocks having a larger impact on volatility than positive shocks. The likelihood ratio tests and goodness of fit support the use of stable Paretian GARCH and TGARCH models over Gaussian models.
\end{abstract}

Keywords: Stock Return; Volatility; Trading Volume; Stable TGARCH

\section{INTRODUCTION}

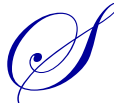

tatistical inferences regarding the empirical studies of financial economics heavily rely on the assumption that the random variables under investigation follow a normal distribution, yet finance data often depart from the assumptions of Gaussian distributions. Daily stock returns are, in general, known to be skewed and leptokurtic rather than normally distributed. Mandelbrot (1963) and Fama (1965) were early advocates of using stable Paretian distributions to examine financial data. While different heavy-tailed distributions, such as Student's $\mathrm{t}$ and Generalized Error Distributions (GED), have been used in the literature, stable distributions have distinct advantages over these distributions. Stable Paretian distributions, which are also called Levy-Pareto distributions, allow for skewness and leptokurtosis and are consistent with the Generalized Central Limit Theorem. This theorem states that regardless of the existence of the variance, the limiting distribution of a sum of independent and identically distributed random variables is stable (Borak, Härdle and Weron, 2005). In spite of these advantages of a stable distribution, this distribution is not well utilized due to complexity of estimation processes.

Although use of stable distributions to analyze financial data has been presented in the literature, the application to GARCH models is relatively new. Paolella and Taschini (2008), Tavares, et al (2008), Curto et al. (2009), and Parrini (2012) use GARCH models with stable Paretian distributions to examine volatility of financial markets, and these models show better results in terms of goodness of fit criteria compared with models using Gaussian distributions. This paper adds to the literature by focusing on the relationship between stock return volatility and trading volumes. Specifically, we examine the volatility of Dow Jones Industrial Average (DJIA) returns and the trading volume by employing stable Paretian stable GARCH and Threshold GARCH (TGARCH) models and determine whether a choice of distributions improves the empirical results.

Lamoureux and Lastrapes (1990) are the first to apply GARCH models to examine the volatility relationship with the trading volume as a proxy for information arrival time according to the mixture of distribution hypothesis (MDH). They find that volume has positive effects on the volatility of stock returns. However, Suominen (2001) presents a theoretical model that incorporates the GARCH-like conditional variance as a function of trading volume and argues that the trading volume and the asset volatility can be either positively or negatively correlated. 
Fong (2003), Darrat, et al. (2003), Chuang, et al. (2009) and others show positive and causal relationships between return volatility and volume traded. Further, Girard and Biswas (2007) support the results found by Lamoureux and Lastrapes by using both developed and emerging markets with asymmetric GARCH models. ${ }^{1}$

\section{STABLE PARETIAN DISTRIBUTIONS AND TGARCH MODEL}

Stable distributions are a rich class of probability distributions that allows skewness and heavy tails, and suitable to model heavy tailed data such as stock returns, and other financial data. Stable distributions do not have an analytic closed form but can be expressed by their characteristic function. Let a stable Paretian distribution, $S_{\alpha \beta}(\delta, c)$, be expressed as its characteristic function:

$$
\begin{aligned}
& \phi_{X}(t)=E\left(e^{i t X}\right)=\exp \left(i \delta t-|c t|^{\alpha}[1+i \beta \operatorname{sgn}(t) w(t, \alpha)]\right), \\
& \text { where } \mathrm{w}(\mathrm{t}, \alpha)= \begin{cases}-\tan \left(\frac{\pi \alpha}{2}\right) & , \quad \alpha \neq 1 \\
(2 / \pi) \ln |\mathrm{t}| & , \quad \alpha=1 .\end{cases}
\end{aligned}
$$

Assume that $-\infty<\mathrm{t}<\infty, 0<\alpha \leq 2,-1 \leq \beta \leq 1, \mathrm{c}>0$, and $-\infty<\delta<\infty$. Symbols $\alpha, \beta$, c, and $\delta$ are respectively called characteristic exponent, skewness, scale, and location parameters. When $\alpha=2$, a stable distribution becomes a Gaussian distribution. The tail thickness increases as $\alpha$ decreases, and the distribution becomes more leptokurtic. When $\beta$ is positive, the distribution is skewed to the right; when negative, it is skewed to the left. If $\beta$ is zero, the distribution becomes symmetric around location parameter $\delta$ (Rachev and Mittnik, 2000).

To examine the stock returns and volume relationships, we assume the following simple mean equation which directly addresses those relationships as shown below:

$y_{t}=\mu+u_{t}$,

where $y_{t}$ is the returns of DJIA, and $u_{t}=\sigma_{t} \varepsilon_{\mathrm{t}}$, with $\varepsilon_{\mathrm{t}} \sim \operatorname{iid} \mathrm{S}_{\alpha, \beta}(0,1) . \mathrm{S}_{\alpha, \beta}(0,1)$ denotes the standard asymmetric stable Paretian distribution with location parameter $(\delta=0)$, and unit scale parameter $(c=1)$. These assumptions simplify the estimation without altering the properties of the stable distribution, and are commonly imposed in the literature.

In this paper, the GARCH $(1,1)$ and TGARCH $(1,1)$ equations for a stable Paretian distribution are modified by adding the daily trading volume $(V)$ in order to analyze how the volume affects the volatility of stock returns. The volume is thought as a proxy variable for unobserved information that flows into the markets and it is assumed to be weakly exogenous. ${ }^{2}$ Because the residual is given in the standard asymmetric stable Paretian distribution, the conditional variance is expressed in terms of the standard deviation form such as:

$\sigma_{t}=\theta_{0}+\theta_{1}\left|u_{t-1}\right|+\eta S_{t-1}\left|u_{t-1}\right|+\phi_{1} \sigma_{t-1}+\gamma \sqrt{V_{t}}$,

where $S_{t-1}=1$ for $u_{t-1}<0$, and $S_{t-1}=0$ for $u_{t-1} \geq 0$. A parameter $\eta$ addresses leverage effects, which indicate that the potential for negative shocks or news to information have a larger impact on volatility than positive shocks. We impose stability conditions to estimate the stable GARCH and TGARCH models so that these processes will have strictly stationary solutions. ${ }^{3}$ When $\eta$ is zero, we have a symmetric GARCH $(1,1)$ process. We note that a Gaussian TGARCH with the volume is given:

\footnotetext{
${ }^{1}$ Taylor (2005) presents comprehensive discussion regarding the volatility of financial assets.

${ }^{2}$ Refer to Engle, et al. (1983) for the definition.

${ }^{3}$ See Curto, et al. (2009).
} 


$$
\sigma_{t}^{2}=\theta_{0}+\theta_{1} u_{t-1}^{2}+\eta S_{t-1} u_{t-1}^{2}+\phi_{1} \sigma_{t-1}^{2}+\gamma V_{t} .
$$

The probability density and the likelihood functions of the stable distribution GARCH and TGARCH models are nontrivial, and a Fast Fourier Transforms (FFT) procedure is employed for the maximum likelihood estimation (MLE) algorithm. In this paper, we follow the MLE procedure presented by Mittnik et al. (1999). Their estimation method deals with conditional heteroskedasticity models with a stable Paretian distribution by employing a computationally efficient density calculation. The MLE estimation with a FFT is based on the characteristic function expressed in equation (1). The optimum estimates of parameter vector $\theta$ for the $S_{\alpha, \beta}(0,1)$ with GARCH models are attained by maximizing the logarithm of the following likelihood function: ${ }^{4}$

$\mathrm{L}\left(\boldsymbol{\theta} ; \mathrm{u}_{1}, \ldots, \mathrm{u}_{\mathrm{T}}\right)=\prod_{t=1}^{T} \sigma_{t}{ }^{l} S_{\alpha, \beta}\left(\varepsilon_{t}\right)$.

DuMouchel (1973) shows that the MLE estimates of a stable density are consistent and asymptotically normal with the covariance matrix given by the inverse of the Fisher information matrix.

\section{EMPIRICAL RESULTS}

Table 1 presents the summary statistics of the data. The sample spans from January 4, 1990 to December 31, 2009, and a total of 5,043 daily observations (5,042 for returns) are obtained from Yahoo finance. DJIA denotes the closing price of the Dow Jones Industrial Average, Returns are the log differences of DJIA, and Volume is the trading volume at the end of day. We use two sets of volume specifications for robustness check. They are the square root of the natural logarithm of volume $\mathrm{V} 1^{*}$ and the square root of the absolute value of the log difference of volume V2*, where taking square root of volume is required due to the specifications of stable GACH and TGACH models given in equation (3). From Table 1, the average daily return is $0.026 \%$ (annualized return of 9.45\%), while the largest daily gain is $10.5 \%$ and the largest loss is $8.2 \%$, resulting in substantial variations in the daily returns. According to the Augmented Dickey and Fuller (ADF) tests, $\mathrm{V}{ }^{*}$ is stationary with intercept and trend at one percent significance level, but nonstationary without trend. $\mathrm{V}^{*}$ is stationary regardless of its specifications. We also used other unit root tests and the results are basically the same. ${ }^{5}$ DJIA and Returns show negative skewness, but Volume series are positively skewed. Returns and $\mathrm{V} 2 *$ show kurtosis, and according to the Jarque-Bera statistics, all variables are non-normally distributed. Further, the residuals from equation (1) indicate strong ARCH effect (not presented).

\section{Table 1: Summary Statistics}

DJIA is the closing price of the Dow Jones Industrial Average, Returns are log differences of DJIA, and Volume is the number of shares traded. V1* and V2* are the square root of the natural logarithm of Volume and the absolute value of the logarithmic difference of Volume, respectively.

\begin{tabular}{|l|c|c|c|c|c|}
\hline & DJIA & Returns & Volume & V1* & V2* \\
\hline Mean & 7878.665 & 0.000260 & $1.42 \mathrm{E}+09$ & 4.527965 & 0.323263 \\
\hline Median & 8773.570 & 0.000460 & $8.81 \mathrm{E}+08$ & 4.538282 & 0.306426 \\
\hline Maximum & 14164.53 & 0.105083 & $1.15 \mathrm{E}+10$ & 4.812671 & 2.761391 \\
\hline Minimum & 2365.100 & -0.0820050 & 2200000 & 3.821514 & 0.000000 \\
\hline Std. Dev. & 3329.070 & 0.011238 & $1.60 \mathrm{E}+09$ & 0.119787 & 0.175573 \\
\hline Skewness & -0.2683290 & -0.118954 & 2.024760 & 0.016763 & 2.314690 \\
\hline Kurtosis & 1.692637 & 11.50240 & 2.27961 & 2.27961 & 20.92803 \\
\hline Jarque-Bera & 419.6614 & 15198.99 & 7231.383 & 109.28 & 72026.12 \\
\hline
\end{tabular}

\footnotetext{
${ }^{4}$ We thank Professor Curto for providing us with the Matlab codes.

${ }^{5}$ The results of unit root tests are available upon request.
} 
Table 2 shows the estimation results of Gaussian and stable Paretian GARCH models. Standard errors and t-statistics are presented in parentheses and in square brackets. For the volume specification of a Gaussian model, the variables V1 and V2 are respectively the natural logarithm of volume and the absolute value of the log difference of volume. As for the cases of $\mathrm{V} 1 *$ and $\mathrm{V} 2 *, \mathrm{~V} 1$ is stationary with intercept and trend but nonstationary without trend, and V2 is always stationary. The parameters of GARCH specifications are significant for both distributions with two volume specifications. The estimates of volume are also significant except Gaussian GARCH with V1, and they are positive. The results indicate that as trading volume increases, so does volatility. Because the trading volume is assumed to be a proxy for unobserved information flow, we conjecture that as information flow increases, the volatility also increases. They support the findings of Lamoureux and Lastrapes (1990) although the GARCH parameters become insignificant after adding the trading volume. From the stable distributions, the estimates of the shape parameter $\alpha$ are statistically significant at the one percent level, and both are less than 2 based on t-tests, implying heavy tailed pattern, i.e., leptokurtic, and rejecting a Gaussian distribution. The estimates of the skewness parameters $\beta$ are negative and significant. Curto et al. (2009) also find the negative skewness parameters for three different equity index returns (including DJIA). These findings are agreeable with the results of unconditional skewness shown in Table 1. The point estimates and the standard errors of $\alpha$ and $\beta$ are similar for both volume specifications.

Table 2: GARCH Models with Volume

V1 and V2 are respectively the natural logarithm of volume and the absolute value of the log difference of volume. V1* and V2* are the square root of the natural logarithm of volume and the square root of the absolute value of the log difference of volume, respectively. Standard errors are presented in parentheses, and t-statistics are in square brackets.

\begin{tabular}{|c|c|c|c|c|}
\hline & \multicolumn{2}{|c|}{$\begin{array}{c}\text { Gaussian } \\
\text { GARCH }\end{array}$} & \multicolumn{2}{|c|}{$\begin{array}{c}\text { Stable } \\
\text { GARCH }\end{array}$} \\
\hline & V1 & V2 & V1* & V2* \\
\hline Intercept & $\begin{array}{c}0.000523 \\
(1.17 \mathrm{E}-04) \\
{[4.47]}\end{array}$ & $\begin{array}{c}0.000526 \\
(1.17 \mathrm{E}-04) \\
{[4.48]}\end{array}$ & $\begin{array}{c}0.000435 \\
(1.22 \mathrm{E}-04) \\
{[3.56]}\end{array}$ & $\begin{array}{c}0.000438 \\
(1.22 \mathrm{E}-04) \\
{[3.60]}\end{array}$ \\
\hline$\theta_{0}$ & $\begin{array}{c}-0.000000 \\
(9.86 \mathrm{E}-07) \\
{[-0.14]}\end{array}$ & $\begin{array}{c}0.000110 \\
(2.62 \mathrm{E}-07) \\
1.43743\end{array}$ & $\begin{array}{c}0.000000 \\
(0.0000) \\
{[0.0000]}\end{array}$ & $\begin{array}{c}0.000056 \\
(3.43 \mathrm{E}-05) \\
{[1.64]}\end{array}$ \\
\hline$\theta_{1}$ & $\begin{array}{c}0.068804 \\
(4.23 \mathrm{E}-03) \\
{[16.29]}\end{array}$ & $\begin{array}{c}0.071088 \\
(0.0043) \\
16.36923\end{array}$ & $\begin{array}{c}0.043011 \\
(4.15 \mathrm{E}-03) \\
{[10.37]}\end{array}$ & $\begin{array}{c}0.043369 \\
(4.17 \mathrm{E}-03) \\
{[10.39]}\end{array}$ \\
\hline$\phi_{1}$ & $\begin{array}{c}0.922403 \\
(5.08 \mathrm{E}-03) \\
{[181.46]}\end{array}$ & $\begin{array}{c}0.918869 \\
(0.0051) \\
{[178.50]}\end{array}$ & $\begin{array}{c}0.926650 \\
(7.31 \mathrm{E}-03) \\
{[126.80]}\end{array}$ & $\begin{array}{c}0.926040 \\
(7.25 \mathrm{E}-03) \\
{[127.60]}\end{array}$ \\
\hline$\gamma$ & $\begin{array}{c}0.0000001 \\
(4.72 \mathrm{E}-08) \\
{[1.23]} \\
\end{array}$ & $\begin{array}{c}0.000006 \\
(1.97 \mathrm{E}-06) \\
{[3.02]} \\
\end{array}$ & $\begin{array}{c}0.000029 \\
(4.53 \mathrm{E}-06) \\
{[6.51]} \\
\end{array}$ & $\begin{array}{c}0.000245 \\
(9.77 \mathrm{E}-05) \\
{[2.50]}\end{array}$ \\
\hline$\alpha$ & - & - & $\begin{array}{c}1.880 \\
(1.95 \mathrm{E}-02) \\
{[96.53]}\end{array}$ & $\begin{array}{c}1.881 \\
(1.94 \mathrm{E}-02) \\
{[96.73]}\end{array}$ \\
\hline$\beta$ & - & - & $\begin{array}{c}-0.368 \\
(1.21 \mathrm{E}-01) \\
{[-3.03]}\end{array}$ & $\begin{array}{c}-0.374 \\
(1.24 \mathrm{E}-01) \\
{[-3.03]}\end{array}$ \\
\hline Log Likelihood & 16444 & 16447 & 16517 & 16518 \\
\hline AIC & -32878 & -32884 & -33032 & -33034 \\
\hline SBC & -32845 & -32852 & -33034 & -33036 \\
\hline
\end{tabular}

The estimation results of Gaussian and stable TGARCH models are reported in Table 3. We observe that the estimates of the conditional variances are statistically significant, though the estimates of ARCH term are not. Also we find that the estimates of volume are positive and significant except Gaussian TGARCH with V1, where they are qualitatively the same as the results found in Table 2. The asymmetric parameters are positive and statistically significant at the one percent level for all specifications, indicating the presence of the leverage effect, i.e., negative residuals have larger effects on the volatility. The results are consistent with the existing literature. These findings support the findings by Girard and Biswas (2007) who present the leverage effects as well as positive 
relationships between volatility and volume. The likelihood ratio tests reject GARCH against TGARCH regardless of the volume specifications. We conclude that there exist strong leverage effects, where negative shocks have larger effect on volatility of DJIA returns. As found in Table 2, the estimates of the stable distributions with the shape parameter $\alpha$ are statistically significant at the one percent level, and the estimates of the skewness parameters $\beta$ are negative and significant.

Table 3: TGARCH Models with Volume

V1 and V2 are respectively the natural logarithm of volume and the absolute value of the log difference of volume. V1* and V2* are the square root of the natural logarithm of volume and the square root of the absolute value of the log difference of volume, respectively. Standard errors are presented in parentheses, and t-statistics are in square brackets.

\begin{tabular}{|c|c|c|c|c|}
\hline & \multicolumn{2}{|c|}{$\begin{array}{c}\text { Gaussian } \\
\text { TGARCH }\end{array}$} & \multicolumn{2}{|c|}{$\begin{array}{c}\text { Stable } \\
\text { TGARCH }\end{array}$} \\
\hline & V1 & $\mathbf{V 2}$ & V1* & V2* \\
\hline Intercept & $\begin{array}{c}0.000282 \\
(1.19 \mathrm{E}-04) \\
{[2.37]}\end{array}$ & $\begin{array}{c}0.000285 \\
(0.00012) \\
(2.41)\end{array}$ & $\begin{array}{c}0.000216 \\
(1.17 \mathrm{E}-04) \\
{[1.84]}\end{array}$ & $\begin{array}{c}0.000222 \\
(1.18 \mathrm{E}-04) \\
{[1.89]}\end{array}$ \\
\hline$\theta_{0}$ & $\begin{array}{c}0.000002 \\
(9.73 \mathrm{E}-07) \\
{[2.07]} \\
\end{array}$ & $\begin{array}{c}0.000006 \\
(0.00000) \\
{[2.57]} \\
\end{array}$ & $\begin{array}{c}0.000000 \\
(0.00000) \\
{[0.00]} \\
\end{array}$ & $\begin{array}{c}0.000051 \\
(2.95 \mathrm{E}-05) \\
{[1.72]}\end{array}$ \\
\hline$\theta_{1}$ & $\begin{array}{c}0.007779 \\
(5.06 \mathrm{E}-03) \\
{[1.54]}\end{array}$ & $\begin{array}{c}0.007197 \\
(0.00529) \\
{[1.36]}\end{array}$ & $\begin{array}{c}0.002704 \\
(4.23 \mathrm{E}-03) \\
{[0.64]}\end{array}$ & $\begin{array}{c}0.002199 \\
(4.28 \mathrm{E}-03) \\
{[0.51]}\end{array}$ \\
\hline$\phi_{1}$ & $\begin{array}{c}0.926318 \\
(5.06 \mathrm{E}-03) \\
{[183.06]} \\
\end{array}$ & $\begin{array}{c}0.924445 \\
(0.00532) \\
{[173.79]} \\
\end{array}$ & $\begin{array}{c}0.937730 \\
(5.89 \mathrm{E}-03) \\
{[159.10]} \\
\end{array}$ & $\begin{array}{c}0.938290 \\
(5.86 \mathrm{E}-03) \\
{[160.00]}\end{array}$ \\
\hline$\eta$ & $\begin{array}{c}0.104815 \\
(7.34 \mathrm{E}-03) \\
{[14.27]} \\
\end{array}$ & $\begin{array}{c}0.107206 \\
(0.00743) \\
{[14.41]} \\
\end{array}$ & $\begin{array}{c}0.067618 \\
(5.43 \mathrm{E}-03) \\
{[12.46]} \\
\end{array}$ & $\begin{array}{c}0.067972 \\
(5.38 \mathrm{E}-03) \\
{[12.62]}\end{array}$ \\
\hline$\gamma$ & $\begin{array}{c}0.0000000 \\
(4.71 \mathrm{E}-08) \\
{[0.75]}\end{array}$ & $\begin{array}{c}0.000006 \\
(1.85 \mathrm{E}-06) \\
{[3.24]}\end{array}$ & $\begin{array}{c}0.000026 \\
(3.66 \mathrm{E}-06) \\
{[7.08]}\end{array}$ & $\begin{array}{c}0.000205 \\
(8.30 \mathrm{E}-05) \\
{[2.47]}\end{array}$ \\
\hline$\alpha$ & - & - & $\begin{array}{c}1.909 \\
(1.74 \mathrm{E}-02) \\
{[109.50]}\end{array}$ & $\begin{array}{c}1.912 \\
(1.73 \mathrm{E}-02) \\
{[110.70]}\end{array}$ \\
\hline$\beta$ & - & - & $\begin{array}{c}-0.559 \\
(1.46 \mathrm{E}-01) \\
{[-3.84]}\end{array}$ & $\begin{array}{c}-0.587 \\
(1.53 \mathrm{E}-01) \\
{[-3.85]}\end{array}$ \\
\hline Log Likelihood & 16502 & 16506 & 16591 & 16592 \\
\hline AIC & -32992 & -32999 & -33179 & -33183 \\
\hline SBC & -32953 & -32960 & -33181 & -33185 \\
\hline
\end{tabular}

From the results presented in Tables 2 and 3, the stable Paretian GARCH and TGARCH models appear to be preferable based on the goodness of fit. The stable GARCH and TGARCH models show higher log likelihood values compared to the Gaussian GARCH and TGARCH models and yield much smaller values of the Akaike Information Criterion (AIC) and Schwartz Information Criterion (SBC). Further, the stable TGARCH specification appears to be a preferable model based on the goodness of fit. The results confirm the advantages of using stable distributions that can take into account the non-normal nature of the time series data examined. However, we point out that difficulty of estimating the stable distribution models compare to Gaussian models because the distribution does not have a closed form analytical form, and is expressed only by its characteristic function.

\section{CONCLUSIONS}

This paper examines the volatility of Dow Jones Industrial Average stock returns and the trading volume by employing stable Paretian GARCH and Threshold GARCH (TGARCH) models. Stable distribution, which includes the normal distribution as a special case, has interesting theoretical and practical properties and has preferable properties that may capture the specific features associated with financial variable such as equity returns. 
Our results indicate that the trading volume significantly contributes to the volatility of stock returns and there exist leverage effects on the stock return volatility. The likelihood ratio tests and goodness of fit support the use of stable Paretian GARCH and TGARCH models over Gaussian models.

\section{AUTHOR INFORMATION}

Dr. Atsuyuki Naka is a Professor at Department of Economics and Finance, the University of New Orleans. He received his Ph.D. in Economics from the University of Arizona. His research areas include applied time series analysis, investments, macro finance, and international finance. E-mail: anaka@ uno.edu (Corresponding author)

Dr. Ece Oral is an Economist at Research and Monetary Policy Department, Central Bank of the Republic of Turkey. She received her Ph.D. in Statistics from Hacettepe University. Her research interests are time series analysis, econometrics, Bayesian statistics, and heavy-tailed distributions. E-mail: ece.oral@tcmb.gov.tr

\section{REFERENCES}

1. $\quad$ Borak, S., Härdle, W., Weron, R., 2005. Stable Distributions, SFB 649 Discussion Paper.

2. Chuang, C., Kuan, C., Lin, H., 2009. Causality in quintiles and dynamic stock return-volume relations, Journal of Banking \& Finance 33, 1351-1360.

3. Curto, J. D., Pinto J. C. and Tavares G. N., 2009. Modeling stock markets' volatility using GARCH models with Normal, Student's t and stable Paretian distributions, Statistical Papers 50, 311-321.

4. Darrat, A.F., Rahman, S., Zhong, M., 2003. Intraday trading volume and return volatility of the DJIA stocks: A note, Journal of Banking \& Finance, 27, 2035-2043.

5. DuMouchel, W. H., 1973. On the asymptotic normality of the maximum likelihood estimate when sampling from a stable distribution, Annals of Statistics, 1, 948-957.

6. $\quad$ Engle, R, Hendry, D, and Richard, F., 1983. Exogeneity, Econometrica 51, 277-304.

7. Fama, E.F., 1965. The behaviour of stock market prices. Journal of Business 38:34-105.

8. Fong, W.M., 2003. Time reversibility test of volume-volatility dynamics for stock returns, Economics Letters 81, 39-45.

9. Girard, E., and Biswas, R., 2007. Trading Volume and Market Volatility: Developed versus Emerging Stock Markets, Financial Review 42, 429-459.

10. Lamoureux, C.G. and Lastrapes, W.D., 1990. Heteroskedasticity in Stock Returns Data: Volume versus GARCH Effect, Journal of Finance 45, 221-230.

11. Mandelbrot, B., 1963. The variation of certain speculative prices. Journal of Business 36, 394-419.

12. Mittnik, S., Rachev, S. T., Doganoglu, T. and Chenyao, D., 1999. Maximum likelihood estimation of stable Paretian models, Mathematical and Computer Modeling, 29, 275-293.

13. Rachev, S., Mittnik, S., 2000. Stable Paretian Models in Finance, Series in Financial Economics and Quantitative Analysis. John Wiley \& Sons Ltd.

14. Paolalla, M. and L. Taschini, 2008. An econometric analysis of emission allowance prices, Journal of Banking \& Finance 32, 2022-2032.

15. Parrini, A., 2012. Indirect estimation of GARCH models with alpha-stable innovations, MPRA Paper 38544, University Library of Munich, Germany.

16. Suominen, M., 2001. Trading Volume and Information Revelation in Stock Markets, Journal of Financial and Quantitative Analysis 36, 545-565.

17. Tavares, A. B., Curto, J.D., and Tavares, G.N, 2008. Modeling heavy tail and asymmetry using ARCH-type models with stable Paretian distribution, Nonlinear Dynamics 51, 231-243.

18. Taylor, S., 2005, Asset Price Dynamics, Volatility, and Prediction, Princeton University Press, NJ. 